\title{
Human papillomavirus-associated small cell carcinoma/neuroendocrine carcinoma of the oropharynx: a report of two cases
}

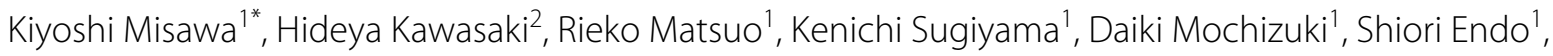 \\ Atushi Imai ${ }^{1}$, Yuki Misawa' ${ }^{1}$,Takashi Yamatodani ${ }^{1}$, Kunihiro Mizuta ${ }^{1}$ and Hiroyuki Mineta ${ }^{1}$
}

\begin{abstract}
Introduction: Small cell carcinoma/neuroendocrine carcinoma (SCNEC) of the oropharynx is uncommon. Two cases of SCNEC in an 81-year-old woman and in a 54-year-old man are presented here.

Case description: We have documented two cases of SCNEC arising in the oropharynx with evidence of high-risk human papillomavirus (HPV) infection. Histologically, both cases were classified as poorly differentiated SCNEC with high nuclear-to-cytoplasmic ratios and nuclear molding. Observations using a transmission electron microscope revealed membrane-bound neuroendocrine granules in some tumor cells. Both tumors expressed high levels of p16, a surrogate marker for high-risk HPV infection. HPV infection was confirmed in both cases using HPV polymerase chain reaction analysis; HPV subtype 16 was identified in one case and HPV subtype 18 in the other.
\end{abstract}

Discussion and Evaluation: SCNEC of the oropharynx is a rare and novel HPV-associated disease with neuroendocrine granules and aggressive clinical behavior.

Conclusions: Herein, we present two cases of SCNEC, focusing on its histologic features and treatment modalities. More studies are required to elucidate the pathophysiology of HPV-associated SCNEC in different organ systems.

\section{Background}

Primary malignant tumors of the oropharynx are usually squamous cell carcinomas (SqCCs). Over the past decade, human papillomavirus (HPV) infection has been recognized as a significant etiological factor for a subset of oropharyngeal SqCCs. Primary small cell carcinoma/ neuroendocrine carcinoma (SCNEC) of the oropharynx is rare. The larynx is the most commonly involved site, followed by the nasal cavity, paranasal sinuses, salivary glands, and oral cavity (Renner 2007; Mineta et al. 2001). Approximately 75 cases of SCNEC in the primary nasal/ paranasal cavities and 180 cases in the larynx have been reported (Sirsath et al. 2013). The prognosis of SCNEC in the nasal cavity and larynx is poor (Chai et al. 2014).

\footnotetext{
*Correspondence: kiyoshim@hama-med.ac.jp

${ }^{1}$ Department of Otolaryngology/Head and Neck Surgery, Hamamatsu University School of Medicine, 1-20-1 Handayama, Hamamatsu, Shizuoka 431-3192, Japan

Full list of author information is available at the end of the article
}

Recently, SCNEC of the uterine cervix and anus have been shown to be associated with HPV infection, and aggressive behavior of HPV-positive SCNEC in the female genital tract has been documented (Mills 2002). Herein, we present the clinical courses of two patients with oropharyngeal HPV-associated SCNEC.

\section{Case 1}

An 81-year-old woman with no history of alcohol consumption or smoking presented with a 3-month history of experiencing a mass in her throat and right-sided neck swelling. On oropharyngoscopy, a tumor was identified in the right anterior wall of the oropharynx (Fig. 1a). Magnetic resonance imaging (MRI) of the neck revealed a $12 \times 15-\mathrm{mm}$ right swollen internal jugular node (Fig. 1b) and a $22 \times 16 \times 24$-mm heterogeneously enhanced tumor that extended through the right anterior wall of the oropharynx (Fig. 1c, d). Fine needle aspiration cytology of a clinically palpable right level II lymph 

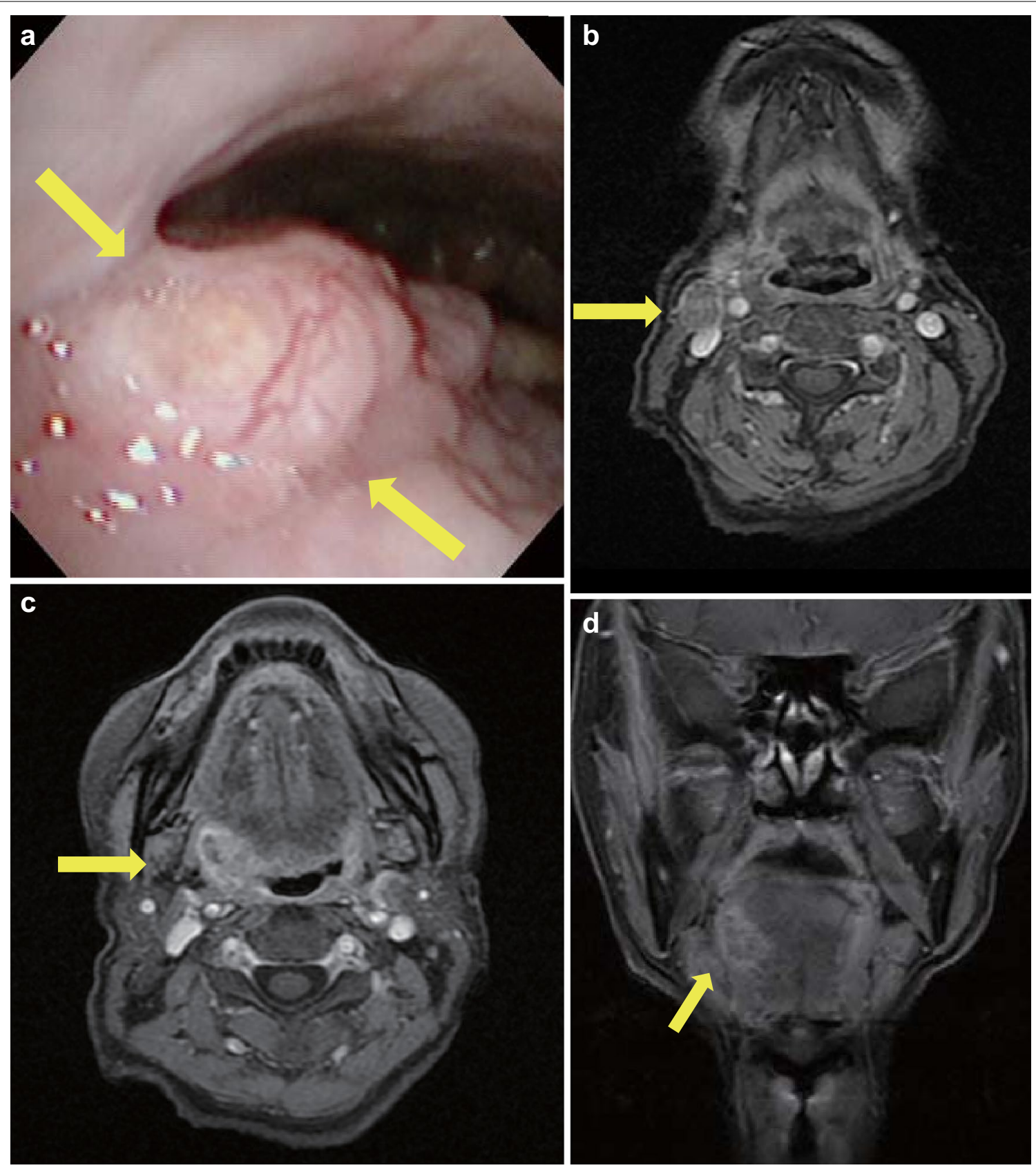

Fig. 1 Case 1. a Oropharyngeal fiberscopic image. A tumor was observed in the right anterior wall of the oropharynx (yellow arrow). b Contrast-axial magnetic resonance imaging (MRI) scan of the neck before treatment. An enhanced metastatic tumor was observed in the right internal jugular node (yellow arrow). c Contrast-axial MRI scan of the neck before treatment. An enhanced primary tumor was observed in the right anterior wall of the oropharynx (yellow arrow). d Contrast-coronal MRI scan (yellow arrow)

node showed features consistent with SqCC. No SCNEC component was identified in the limited biopsy sample obtained from the tumor. The tumor was positive for AE1/AE3 and negative for CD3, CD56, CD79a, synaptophysin, and chromogranin A expression. Subsequently, a pathologist analyzed the biopsy sample and diagnosed the lesion as SqCC. A partial pharyngectomy with right neck dissection was performed, and the malignancy was diagnosed as SCNEC. Histologic examination revealed small, round to oval tumor cells arranged in cords or 
Table 1 Summary of the demographic details, immunohistochemistry profiles, and results of HPV tests for Cases 1 and 2

\begin{tabular}{lll}
\hline & Case $\mathbf{1}$ & Case 2 \\
\hline Year of diagnosis & 2010 & 1995 \\
Age at diagnosis (years) & 81 & 54 \\
Sex & Female & Male \\
Primary site & Base of tongue & Left tonsil \\
TN stage & T2N1 & T2N2b \\
Treatment & Surgery & Irradiation (70 Gy) + \\
& & chemotherapy (cisplatin \\
& & + etoposide) \\
Synaptophysin & Positive & Negative \\
Chromogranin A & Negative & Positive \\
CD56 & Positive & Positive \\
TEM & Granules & Granules \\
p16 & Positive & Positive \\
HPV test & Type16 & Type18 \\
Follow-up interval & 22 & 10 \\
(month) & & \\
Outcome & Dead of disease & Dead of disease
\end{tabular}

nests, containing hyperchromatic nuclei and mitotic figures; the tumor was positive for synaptophysin and CD56 and negative for chromogranin A expression (Table 1). The patient was diagnosed with T2N1M0 oropharyngeal SCNEC, according to the 2009 Union for International Cancer Control staging system. After surgery, the patient refused radiotherapy and chemotherapy. Patient details are summarized in Table 1.

\section{Case 2}

A 54-year-old man, with a 30-year history of excessive alcohol consumption and smoking, presented with a 10-month history of throat pain and experiencing a mass in his throat. He had no history of weight loss, dysphagia, or dyspnea. On oropharyngoscopy, a tumorous lesion with ulcerating mucosa was found in the left palatine tonsil (Fig. 2a). A contrast computed tomography scan of the neck also revealed a homogeneously enhanced tumor in the left palatine tonsil (Fig. 2b). MRI examination of the neck revealed a $30 \times 20 \times 38$-mm heterogeneously enhanced tumor of the oropharynx (Fig. 2c) and bilateral cervical lymph node metastasis (Fig. 2d). The patient was diagnosed with T2N2bM0 oropharyngeal cancer. A pathologist analyzed the biopsy sample of the left palatine tonsil and diagnosed the lesion as SCNEC. The patient was treated with sequential chemoradiotherapy. Following 4 induction cycles of cisplatin and etoposide, he underwent radiotherapy for the right palatine tonsil and neck (70 Gy). Patient details are summarized in Table 1.

\section{Pathology}

Hematoxylin-eosin staining revealed a component with more anaplastic features typical of SCNEC, such as sheets of tightly packed anaplastic cells with round nuclei and scant cytoplasm (Fig. 3a, c). Immunohistochemi$\mathrm{cal}$ analyses revealed that malignant cells expressed high levels of cytoplasmic p16 (Fig. 3b, d). Positivity for p16 was defined by strong and diffuse nuclear and cytoplasmic staining in more than $70 \%$ of cells. Both cases exhibited a high p16-positive/Rb-negative/cyclin D1-negative immunophenotype (Additional file 1: Figure S2). Neuroendocrine differentiation was investigated using immunohistochemical techniques. Both cases showed neuroendocrine features, including staining for synaptophysin, chromogranin A, and CD56 (Table 1). The following primary antibodies were used: p16 (clone G175-405; BioGenex), cyclin D1 (clone SP4; NICHIREI), Rb (clone PDM111; DBP), AE1/AE3 (clone AE1/AE3; Leica), CD3 (clone LN10; Leica), CD56 (clone 1B6; Leica), CD79a (clone JCB117; Dako), synaptophysin (clone 27G12; Leica), and chromogranin A (Dako).

\section{Transmission electron microscopy studies}

Transmission electron microscopy (TEM) studies were performed for both cases to detect neurosecretory granules. TEM specimens were fixed in $2 \%$ phosphate buffered glutaraldehyde overnight, rinsed in $0.1 \mathrm{~mol} / \mathrm{L}$ phosphate buffer ( $\mathrm{pH} 7.4$ ), post-fixed in $1 \%$ phosphate buffered osmium tetroxide, and dehydrated in epoxy resin. Semi-thin sections from selected areas were stained with uranyl acetate and lead citrate and examined using TEM. TEM evaluation revealed dense-core neurosecretory granules in the cytoplasm of cells in the specimens of both patients (Fig. 4a, b).

\section{DNA extraction, HPV polymerase chain reaction, and HPV type sequencing}

DNA was isolated from the SCNEC elements of specimens obtained during surgery. Genomic DNA was extracted from frozen tumor specimens using the QIAamp DNA Mini Kit (QIAGEN, Hilden, Germany), according to the manufacturer's instructions.

HPV status was determined using the HPV Typing Set (Takara Bio., Tokyo, Japan), a primer set for polymerase chain reaction (PCR) specifically designed to identify HPV genotypes $16,18,31,33,35,52$, and 58 using genomic DNA. The PCR HPV Typing Set method was performed according to the manufacturer's instructions. Specimens from both patients tested positively for highrisk HPV. After amplification, HPV typing revealed a 238-bp band for HPV-16 in case 1 and a 268-bp for HPV18 in case 2 (Fig. 5). PCR products were extracted and sequenced using a computed automatic DNA sequencer 

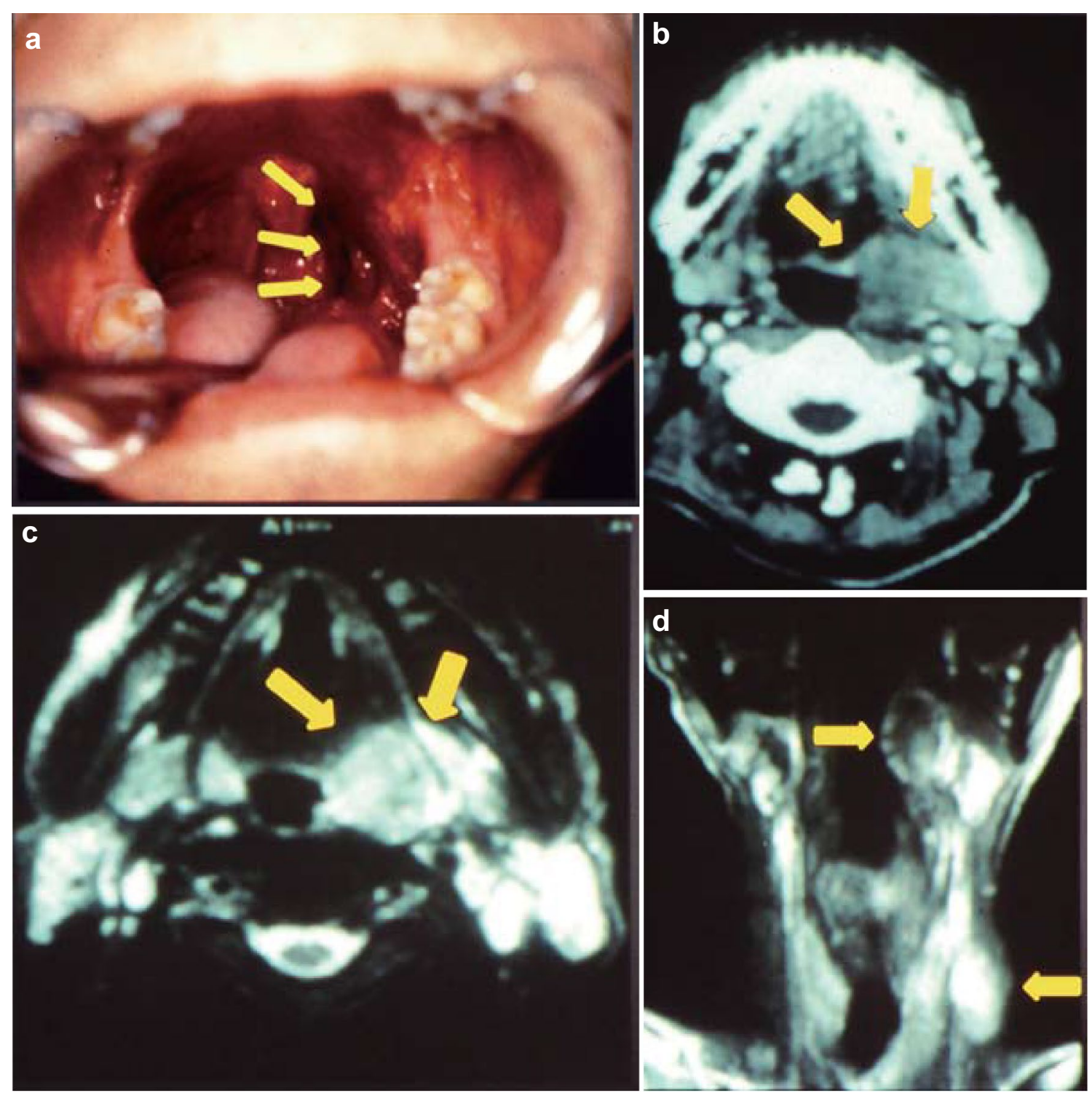

Fig. 2 Case 2. a Oropharyngeal image. An ulcerated tumor was observed in the left palatine tonsil (yellow arrow). An enhanced tumor was observed in the left palatine tonsil on the contrast-axial computed tomography scan of the neck (yellow arrow) (b), contrast-axial magnetic resonance imaging (MRI) scan (yellow arrow) (c), and contrast-coronal-MRI scan (yellow arrow) (d)

(ABI PRIZM 3100 Genetic Analyzer; Applied Biosystems, ABI, CA) (Additional file 2: Figure S1).

\section{Discussion}

The worldwide incidence and prevalence of HPV-associated oropharyngeal cancer have been increasing over time. Among the head and neck regions, SCNEC most commonly arises in the larynx, but it has also been reported in the sinonasal tract and salivary glands (Renner 2007; Mineta et al. 2001). SCNECs of the oropharynx are extremely rare, and only 40 cases have been reported since it was first identified by Koss et al. (1972) (Wang et al. 2014; Watson et al. 2013; Kraft et al. 2012; Bishop and Westra 2011). Recently, an association between oropharyngeal SCNEC and high-risk HPV infection was reported (Watson et al. 2013; Kraft et al. 2012; Bishop and Westra 2011). An oncogenic HPV status has been described in 14/19 (73.7\%) cases of oropharyngeal SCNEC (Watson et al. 2013; Kraft et al. 2012; Bishop and Westra 2011). HPV infection confers a better prognosis for patients with oropharyngeal SqCC and basaloid SqCC (Gillison et al. 2000; Jacobi et al. 2015). However, 

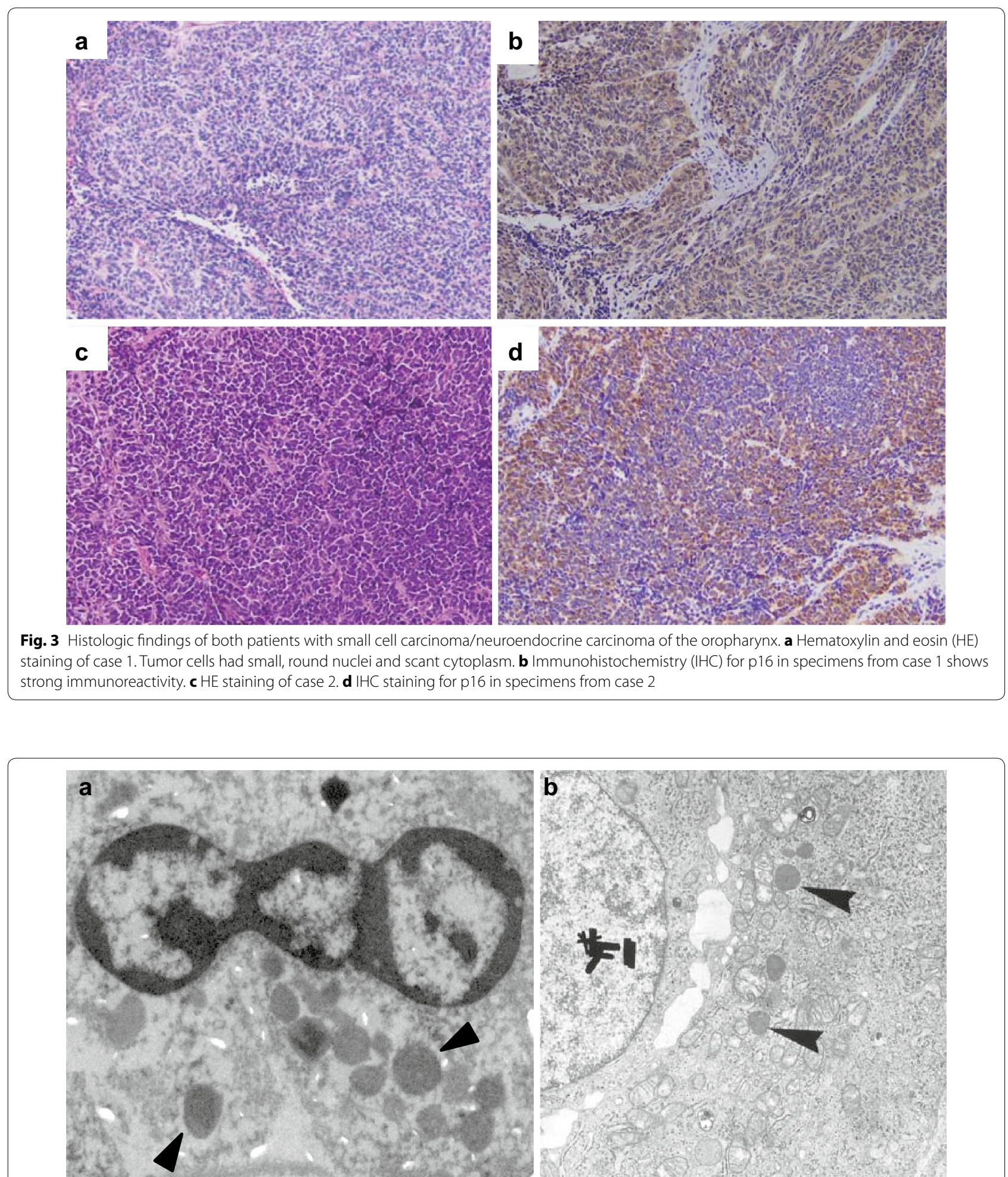

Fig. 4 Transmission electron microscopy (TEM) demonstrates dense-core neurosecretory granules (black arrowheads). a TEM of a specimen from case 1. $\mathbf{b}$ TEM of a specimen from case 2 


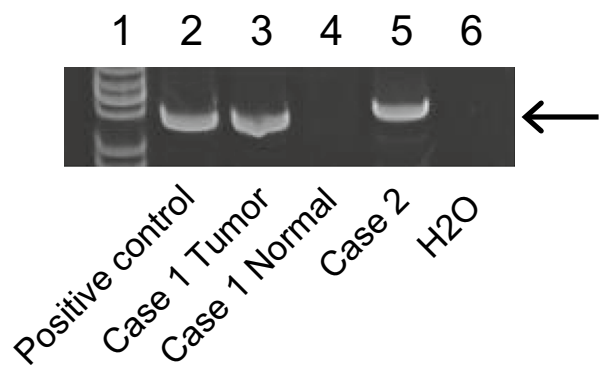

Fig. 5 Electrophoresis to assess human papillomaviruses (HPV) status. The bands in lane 3 represent positive reactivity for HPV-16 in case 1 . The band in lane 4 represents negative reactivity for HPV in adjacent normal mucosal tissues of case 1. The bands in lane 5 represent positive reactivity for HPV-18 in case 2. Lane 2 contains an extract from a control cell line that is known to be HPV-16-positive (UMSCC-47; a gift from Dr. TE Carey). The DNA size marker is located in lane 1. The water blank is in lane 6

the prognosis of patients with SCNEC of the oropharynx is poor, as the majority of patients die of the disease mainly due to systemic metastasis (Renner 2007; Wang et al. 2014).

Gynecologic extrapulmonary SCNECs most commonly arise in the cervix, and SCNECs of the uterine cervix comprise less than $3 \%$ of cervical cancers (Cohen et al. 2010). SCNECs of the uterine cervix are highly aggressive with extensive local invasion and distant metastases. Most small cell carcinomas of the uterine cervix exhibit neuroendocrine differentiation and ultrastructural examination may be considered the most reliable method for confirming this feature (Ishida et al. 2004). HPV has been detected in more than $90 \%$ of SCNEC tumors through PCR sequencing analysis (Wang and Lu 2004; Horn et al. 2006; Masumoto et al. 2003; Ishida et al. 2004). Many studies have shown that SCNECs that express the HPV oncoproteins E6 and E7 have high levels of p16 (Wang and $\mathrm{Lu}$ 2004; Horn et al. 2006; Masumoto et al. 2003). In general, all SCNECs tend to be locally aggressive and have a strong propensity for both regional and distant metastases (Renner 2007).

The diagnosis of SCNEC requires immunohistochemical or ultrastructural studies. With routine hematoxylin and eosin staining, SCNEC exhibits morphology similar to that of nonkeratinizing SqCC. A case with a histopathologic finding of small round cells with scant cytoplasm should be evaluated for synaptophysin, chromogranin A, and CD56 expression, followed by ultrastructural analysis to detect neurosecretory granules in the tumor cells (Mineta et al. 2001). Recently, Alos et al. reported an inverse association between p16 expression and expression of Rb and cyclin D1 in SCNEC. The most prevalent phenotype was high p16-positive/Rb-low or -negative/cyclin D1-low or -negative expression (14/19, $73.7 \%)$. Thus, patchy p16 positivity/strong $\mathrm{Rb}$ nuclear staining/strong cyclin D1 nuclear staining was observed in $5 / 19$ cases (26.3\%) (Alos et al. 2016).

Owing to the rarity of these tumors, recommendations for the management of SCNEC of the oropharynx have not been established (Barbeaux et al. 2006). Most patients die within 2 years of diagnosis, despite being treated with adjuvant radiation and chemotherapy (Aggarwal et al. 2010). On the basis of comparative treatments for SCNEC of the larynx and lungs, various modalities have been indicated for patients with SCNEC of the oropharynx (Jaiswal and Hoang 2004).

In conclusion, SCNEC of the oropharynx is extremely rare and highly aggressive, with a poor prognosis. Herein, we present two cases of SCNEC, focusing on its histologic features and treatment modalities. More studies are required to elucidate the pathophysiology of HPV-associated SCNEC in different organ systems.

\section{Additional files}

Additional file 1: Figure S2. Expression of Rb and cyclin D1 (A) Absolutely negative Rb expression in case 1. (B) Absolutely negative cyclin D1 expression in case 1. (C) Rb expression staining in case 2. (D) IHC staining for cyclin D1 in specimens from case 2.

Additional file 2: Figure S1. (A) Electropherogram of a case 1 extract that contains a relative sequence of the human papillomaviruses (HPV)-16 E7 region. (B) Electropherogram of a case 2 extract that contains a relative sequence of the HPV-18E7 region.

\section{Authors' contributions}

KM and TY performed the medical treatment and evaluated the patient. YM, $\mathrm{DM}$, and SE revised the manuscript and evaluated the patient. Al, RM, KS, and $\mathrm{HM}$ reviewed the charts and published literature. HK and KM performed pathological investigations and electron microscopy analysis. All authors read and approved the final manuscript.

\section{Author details}

${ }^{1}$ Department of Otolaryngology/Head and Neck Surgery, Hamamatsu University School of Medicine, 1-20-1 Handayama, Hamamatsu, Shizuoka 431-3192, Japan. ${ }^{2}$ Department of Regenerative and Infectious Pathology, Hamamatsu University School of Medicine, Hamamatsu, Japan.

\section{Acknowledgements}

The authors would like to thank Ms. Yuko Mohri for her excellent technical support.

\section{Competing interests}

The authors declare that they have no competing interests.

\section{Patient consent}

The patients consented to the publication of this case report (IRB of Hamamatsu University School of Medicine).

Received: 3 May 2016 Accepted: 10 October 2016

Published online: 22 October 2016 


\section{References}

Aggarwal G, Jackson L, Sharma S (2010) Primary combined small cell carcinoma of larynx with lateralized histologic components and corresponding side-specific neck nodal metastasis: report of a unique case and review of literature. Int J Clin Exp Pathol 4(1):111-117

Alos L, Hakim S, Larque AB, de la Oliva J, Rodriguez-Carunchio L, Caballero M, Nadal A, Marti C, Guimera N, Fernandez-Figueras MT, Quint W, Ordi J (2016) p16 overexpression in high-grade neuroendocrine carcinomas of the head and neck: potential diagnostic pitfall with HPV-related carcinomas. Virchows Arch Int J Pathol 469(3):277-284. doi:10.1007/ s00428-016-1982-1

Barbeaux A, Duck L, Weynand B, Desuter G, Hamoir M, Gregoire V, Baurain JF, Machiels JP (2006) Primary combined squamous and small cell carcinoma of the larynx: report of two cases and discussion of treatment modalities. Eur Arch Otorhinolaryngol 263(8):786-790. doi:10.1007/ s00405-006-0060-8

Bishop JA, Westra WH (2011) Human papillomavirus-related small cell carcinoma of the oropharynx. Am J Surg Pathol 35(11):1679-1684. doi:10.1097/PAS.0b013e3182299cde

Chai L, Ying HF, Wu TT, Zhou SH, Bao YY, Yao HT, You QH (2014) Clinical features and hypoxic marker expression of primary sinonasal and laryngeal smallcell neuroendocrine carcinoma: a small case series. World J Surg Oncol 12:199. doi:10.1186/1477-7819-12-199

Cohen JG, Kapp DS, Shin JY, Urban R, Sherman AE, Chen LM, Osann K, Chan JK (2010) Small cell carcinoma of the cervix: treatment and survival outcomes of 188 patients. Am J Obstet Gynecol 203(4):341-346. doi:10.1016/j.ajog.2010.04.019

Gillison ML, Koch WM, Capone RB, Spafford M, Westra WH, Wu L, Zahurak ML, Daniel RW, Viglione M, Symer DE, Shah KV, Sidransky D (2000) Evidence for a causal association between human papillomavirus and a subset of head and neck cancers. J Natl Cancer Inst 92(9):709-720

Horn LC, Lindner K, Szepankiewicz G, Edelmann J, Hentschel B, Tannapfel A, Bilek K, Liebert UG, Richter CE, Einenkel J, Leo C (2006) p16, p14, p53, and cyclin D1 expression and HPV analysis in small cell carcinomas of the uterine cervix. Int I Gynecol Pathol Off J Int Soc Gynecol Pathol 25(2):182-186. doi:10.1097/01.pgp.0000185406.85685.df

Ishida GM, Kato N, Hayasaka T, Saito M, Kobayashi H, Katayama Y, Sasou S, Yaegashi N, Kurachi H, Motoyama T (2004) Small cell neuroendocrine carcinomas of the uterine cervix: a histological, immunohistochemical, and molecular genetic study. Int J Gynecol Pathol Off J Int Soc Gynecol Pathol 23(4):366-372
Jacobi C, Ayx I, Fritsche K, Piontek G, Hoffmann D, Weirich G, Knopf A (2015) Potential impact of human papilloma virus on survival of basaloid squamous carcinoma of the head and neck. Oncotarget 6(5):3462-3470. doi:10.18632/oncotarget.3062

Jaiswal VR, Hoang MP (2004) Primary combined squamous and small cell carcinoma of the larynx: a case report and review of the literature. Arch Pathol Lab Med 128(11):1279-1282. doi:10.1043/1543-2165(2004)128<1279:PCS ASC $>2.0 . C O ; 2$

Koss LG, Spiro RH, Hajdu S (1972) Small cell (oat cell) carcinoma of minor salivary gland origin. Cancer 30(3):737-741

Kraft S, Faquin WC, Krane JF (2012) HPV-associated neuroendocrine carcinoma of the oropharynx: a rare new entity with potentially aggressive clinical behavior. Am J Surg Pathol 36(3):321-330. doi:10.1097/ PAS.0b013e31823f2f17

Masumoto N, Fujii T, Ishikawa M, Saito M, Iwata T, Fukuchi T, Susumu N, Mukai M, Kubushiro K, Tsukazaki K, Nozawa S (2003) P16 overexpression and human papillomavirus infection in small cell carcinoma of the uterine cervix. Hum Pathol 34(8):778-783

Mills SE (2002) Neuroectodermal neoplasms of the head and neck with emphasis on neuroendocrine carcinomas. Modern Pathol Off J US Can Acad Pathol 15(3):264-278. doi:10.1038/modpathol.3880522

Mineta H, Miura K, Takebayashi S, Araki K, Ueda Y, Harada H, Misawa K (2001) Immunohistochemical analysis of small cell carcinoma of the head and neck: a report of four patients and a review of sixteen patients in the literature with ectopic hormone production. Ann Otol Rhinol Laryngol 110(1):76-82

Renner G (2007) Small cell carcinoma of the head and neck: a review. Semin Oncol 34(1):3-14. doi:10.1053/j.seminoncol.2006.10.024

Sirsath NT, Babu KG, Das U, Premlatha CS (2013) Paranasal sinus neuroendocrine carcinoma: a case report and review of the literature. Case Rep Oncol Med 2013:728479. doi:10.1155/2013/728479

Wang HL, Lu DW (2004) Detection of human papillomavirus DNA and expression of $\mathrm{p} 16, \mathrm{Rb}$, and $\mathrm{p} 53$ proteins in small cell carcinomas of the uterine cervix. Am J Surg Pathol 28(7):901-908

Wang HY, Zou J, Zhou GY, Yan JQ, Liu SX (2014) Primary small cell neuroendocrine carcinoma of the tonsil: a case report and review of the literature. Int J Clin Exp Pathol 7(5):2678-2682

Watson RF, Chernock RD, Wang X, Liu W, Ma XJ, Luo Y, Wang H, El-Mofty SK, Lewis JS Jr (2013) Spindle cell carcinomas of the head and neck rarely harbor transcriptionally-active human papillomavirus. Head Neck Pathol 7(3):250-257. doi:10.1007/s12105-013-0438-z

\section{Submit your manuscript to a SpringerOpen ${ }^{\circ}$ journal and benefit from:}

- Convenient online submission

- Rigorous peer review

- Immediate publication on acceptance

- Open access: articles freely available online

- High visibility within the field

- Retaining the copyright to your article

Submit your next manuscript at $\boldsymbol{\nabla}$ springeropen.com 